\title{
Urine Calcium/Citrate Ratio in Children With Hypercalciuric Stones
}

\author{
TARAK SRIVASTAVA, MARK J. WINSTON, ARI AURON, AND URI S. ALON
}

\begin{abstract}
Bone and Mineral Disorder Clinic [T.S., M.J.W., U.S.A.], University of Missouri at Kansas City, Kansas City, Missouri 64108; Section of
\end{abstract} Pediatric Nephrology [A.A.], Blank Children's Hospital, Iowa Health System, Des Moines, Iowa 50309

\begin{abstract}
Hypercalciuria is a common cause for stone formation in children. The aim was to delineate the role of urinary citrate in hypercalciuric children for protection against calcium stone formation. We evaluated random urine calcium, citrate, and creatinine in 149 controls, 78 hypercalciuric nonstone formers, and 34 hypercalciuric children with stone. Urine citrate/creatinine was highest in hypercalciuric nonstone formers $899 \pm 351$ compared with controls $711 \pm 328$ and stone formers $595 \pm 289(p<0.01$ vs. both). Calcium/creatinine ratio was similar in hypercalciuric stone and nonstone formers, but significantly higher than controls. Consequently, urine Calcium/citrate ratio $(\mathrm{mg} / \mathrm{mg})$ increased from control $0.17 \pm 0.17$ to $0.41 \pm 0.23(p<0.001)$ in hypercalciuric nonstone formers, and to $0.65 \pm 0.46$ in stone formers $(p<0.001$ compared with other groups). Area under receiver operating characteristic curve combined with multilevel risk analyses found calcium/citrate ratio of 0.326 to provide good discrimination between control and stone formers. We found 5 th percentile for random urine citrate/creatinine ratio in school-aged children to be $176 \mathrm{mg} / \mathrm{g}$, elevated urinary citrate excretion in hypercalciuric children to be protective against stone formation, and urine calcium/citrate ratio to be a good indicator for risk of stone formation. Whether intervention in hypercalciuric children to lower urine calcium/citrate $<0.326$ will provide protection against stone formation needs to be studied. (Pediatr Res 66: 85-90, 2009)
\end{abstract}

$\mathrm{T}^{\mathrm{s}}$ he incidence of urolithiasis in children has increased in recent years (1). The risk factors for urolithiasis commonly observed in children are low urine volume, increased urine calcium excretion, and low normal or decreased urinary citrate level (2). Citrate inhibits the spontaneous nucleation of calcium oxalate, crystal growth of calcium oxalate and calcium phosphate, and the heterogeneous nucleation of calcium oxalate by monosodium urate (3-8). Bisaz et al. (9) reported that citrate is responsible for $50 \%$ of the inhibitory activity against calcium phosphate precipitation in normal urine. The inhibitory effect of citrate on calcium oxalate crystal growth and aggregation is also linked to a direct effect on the crystal surface $(3,10)$. Consequently, and because of lack of significant adverse effects, citrate preparations are widely used in subjects with calcium oxalate nephrolithiasis $(2,11-13)$.

Received September 22, 2008; accepted February 18, 2009

Correspondence: Tarak Srivastava, M.D., Section of Nephrology, The Children's Mercy Hospital, 2401 Gillham Road, Kansas City, MO 64108; e-mail: tsrivastava@cmh.edu

Supported by the Sam and Helen Kaplan Research Fund in Pediatric Nephrology and Eric McClure Research Fund in Pediatric Bone and Mineral Disorders.
In adult studies, Welshman and McGeown (14), Hobarth and Hofbauer (15) and Nikkila et al. (16) observed that urine calcium/citrate ratio was able to discriminate between stone formers and control population; the latter exhibiting a significantly lower calcium/citrate ratio. However, it was the impression in the above studies that the clinical use of urine calcium/citrate ratio was limited because of its wide range of variability and the influence of age and gender on urinary excretion of citrate. There is limited data on urine calcium/ citrate ratio in either healthy, hypercalciuric, or stone forming children $(17,18)$. Treatment of stone formers with citrate raises the theoretical concern of increased formation of calcium phosphate crystals in alkaline urine. Currently, no good tools are available to monitor (or target) potassium citrate therapy in children. Furthermore, it is yet unclear why many other symptomatic hypercalciuric children presenting with dysuria-frequency, abdominal/back pain, and microscopic hematuria do not develop kidney stones. Therefore, the objectives of the study were to investigate whether urinary calcium/ citrate ratio will be helpful in discriminating between healthy children, hypercalciuric nonstone formers, and hypercalciuric stone formers, and consequently whether it can be used as a tool to target therapy in children with calcium stones. In the textbook of Pediatric Nephrology 5th ed. Milliner (19) indicates the unclarity of normative data of urine citrate by quoting both values of 180 and $400 \mathrm{mg} / \mathrm{g}$. We also thought to use this opportunity to establish normative data of urine citrate/creatinine ratio.

\section{MATERIALS AND METHODS}

Random nonfasting urine samples from children between the ages of 5 and $18 \mathrm{y}$ on regular diet were obtained at their initial presentation. They were measured for calcium, citrate, and creatinine in three groups of children: i) healthy control (group C), ii) nonstone forming children with hypercalciuria (group $\mathrm{H}$ ), and iii) hypercalciuric stone forming children (group $\mathrm{S}_{\mathrm{H}}$ ). The inclusion criteria for group $\mathrm{C}$ were children who presented to our clinic with monosymptomatic primary nocturnal enuresis and had a normal physical examination and urinalysis. Group $\mathrm{H}$ were children who presented to our clinic with hypercalciuria associated with either voiding symptoms (frequencydysuria syndrome) or microscopic hematuria, and without clinical symptoms attributable to urolithiasis. Hypercalciuria was defined as urine calcium/ creatinine ratio $\left(\mathrm{U}_{\mathrm{Ca} / \mathrm{Cr}}\right)>0.2 \mathrm{mg} / \mathrm{mg}(20,21)$. Imaging studies in group $\mathrm{H}$ were done at the discretion of the attending physician. Group $\mathrm{S}_{\mathrm{H}}$ included hypercalciuric children with urolithiasis confirmed by an imaging study

\footnotetext{
Abbreviations: ROC, receiver operating characteristic curve; $\mathbf{U}_{\mathbf{C a} \text { /Cit }}$, urine calcium/citrate ratio; $\mathbf{U}_{\mathbf{C a} / \mathbf{C r}}$, urine calcium/creatinine ratio, $\mathbf{U}_{\mathbf{C i t} / \mathbf{C r}}$, urine citrate/creatinine ratio
} 
(x-ray, CT, or ultrasound) and/or stone analysis. Children with uric acid, cystine, or struvite stones were excluded from the study. Children with primary or secondary hyperoxaluria or hypocitraturia were not included in the study so as to exclude the independent effect of hyperoxaluria or hypocitraturia on hypercalciuric stone formers. Similarly, we excluded all those with anatomical or functional abnormalities of the kidney and urinary tract, and gastrointestinal tract.

In each participant, we recorded the ethnicity, gender, age, results of the imaging studies, and/or stone analysis when applicable. At the initial clinic visit, urine creatinine $\left(\mathrm{U}_{\mathrm{Cr}}\right)$, citrate $\left(\mathrm{U}_{\mathrm{Cit}}\right)$, and calcium $\left(\mathrm{U}_{\mathrm{Ca}}\right)$ were measured on the Roche Cobas Mira Classic by kinetic Jaffe, enzymatic (citrate lyase), and cresolphthalein complexone methods, respectively. The $\mathrm{U}_{\mathrm{Ca} / \mathrm{Cr}}$ and urine calcium/citrate ratio $\left(\mathrm{U}_{\mathrm{Ca} / \mathrm{Cit}}\right)$ ratio were expressed as $\mathrm{mg} / \mathrm{mg}$, and urine citrate/creatinine ratio $\left(\mathrm{U}_{\mathrm{Cit} / \mathrm{Cr}}\right)$ as $\mathrm{mg} / \mathrm{g}$. Once the raw data were available, the normal percentile distribution of $\mathrm{U}_{\mathrm{Cit} / \mathrm{Cr}}$ in group $\mathrm{C}$ was calculated. Subsequently, children with documented hypocitraturia $\left(\mathrm{U}_{\mathrm{Cit} / \mathrm{Cr}}<180 \mathrm{mg} / \mathrm{g}\right)$ were excluded from further analysis to ensure that the analysis includes only children with isolated hypercalciuria.

As children in all groups were predominantly ( $>95 \%)$ White, we did not analyze the effect of ethnicity. To evaluate the possible impact of age and gender, the data were analyzed twice; with and without adjustment for age and gender. For statistical analysis, analysis of covariance with Bonferroni correction was used to compare multiple groups. In addition, we compared the predictive power of urinary ratios for identifying stone risk using receiver operating characteristic curves (ROC) and multilevel likelihood ratios. The data were analyzed using SPSS version 15.0 statistical software. A $p$ value

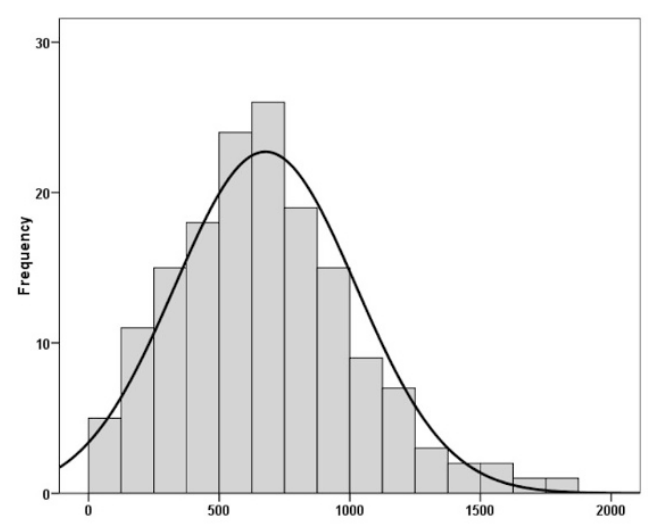

Figure 1. The Gaussian distribution of urine citrate/creatinine from random urine specimen in 158 healthy school-age children with monosymptomatic nocturnal enuresis. The 5 th percentile is at 176,25 th percentile at 419,50 th percentile at 638,75 th percentile at 880 , and 95 th percentile at $1311 \mathrm{mg} / \mathrm{g}$.
$<0.05$ was regarded as statistically significant. The study was approved as an exempt study by the Institutional Review Board of Children's Mercy Hospital of Kansas City (No 05 10-138E) and thus the need to obtain informed consent was waived.

\section{RESULTS}

There were 158 children in group $\mathrm{C}, 78$ in group $\mathrm{H}$, and 37 in group $S_{\mathrm{H}}$. Figure 1 depicts the normal percentile distribution of $\mathrm{U}_{\mathrm{Cit} / \mathrm{Cr}}$ in group $\mathrm{C}$, establishing the 5 th percentile at $176 \mathrm{mg} / \mathrm{g}$. Nine children in group C (4.4\%) and three in group $\mathrm{S}_{\mathrm{H}}(8.1 \%)$ who met the literature criterion of hypocitraturia $\left(\mathrm{U}_{\mathrm{Cit} / \mathrm{Cr}}<180 \mathrm{mg} / \mathrm{g}\right)$, compatible with the 5th percentile of our normal population, were deleted from further analysis (22). Thus, leaving 149 children in group C ( 89 boys/60 girls, $10.02 \pm 2.82 \mathrm{y}$ ), 78 children in group $\mathrm{H}(26$ boys $/ 52$ girls, $7.83 \pm 2.25 \mathrm{y}, p=<0.001$ compared with $C)$ and 34 children in group $\mathrm{S}_{\mathrm{H}}(15$ boys/19 girls, $10.66 \pm 3.22 \mathrm{y}, p=0.65$ compared with $\mathrm{C}$ and $p=$ $<0.001$ compared with $\mathrm{H}$ ). In group $\mathrm{H}, 35$ children $(45 \%)$ had imaging studies that confirmed the absence of urolithiasis. In group $S_{H}$ stone analysis was available in 20 of 34 children who were composed of either pure calcium oxalate dihydrate $(7 / 20)$, calcium oxalate monohydrate $(1 / 20)$ or calcium phosphate $(1 / 20)$, or a mixture $(11 / 20)$ of these calcium salts.

Comparison of urine biochemistry among controls $(C)$, hypercalciuric without stone $(H)$, and hypercalciuric with stone $\left(\boldsymbol{S}_{\boldsymbol{H}}\right)$. Table 1 shows the comparison of $\mathrm{U}_{\mathrm{Ca} / \mathrm{Cr}}, \mathrm{U}_{\mathrm{Cit} / \mathrm{Cr}}$, and $\mathrm{U}_{\mathrm{Ca} / \mathrm{Cit}}$ among the three groups. As shown in Table 1 and Figure 2, and by definition, $\mathrm{U}_{\mathrm{Ca} / \mathrm{Cr}}$ was significantly lower in group $\mathrm{C}$ compared with groups $\mathrm{H}$ and $\mathrm{S}_{\mathrm{H}}$, with no difference between the latter two. The $\mathrm{U}_{\mathrm{Cit} / \mathrm{Cr}}$ value was significantly higher in group $\mathrm{H}$, compared with $\mathrm{C}$ and $\mathrm{S}_{\mathrm{H}}$; which had no difference between themselves. The $\mathrm{U}_{\mathrm{Ca} / \mathrm{Cit}}$ ratio increased significantly from group $\mathrm{C}$ to group $\mathrm{H}$ to group $\mathrm{S}_{\mathrm{H}}$. Gender had no effect on these ratios but Pearson's correlation found $\mathrm{U}_{\mathrm{Ca} / \mathrm{Cr}}$ to decrease with age $(\mathrm{r}=-0.21, p=0.001), \mathrm{U}_{\mathrm{Cit} / \mathrm{Cr}}$ to

Table 1. $U_{\mathrm{Ca} / \mathrm{Cr}}, U_{\mathrm{Cit} / \mathrm{Cr}}$ and $U_{\mathrm{Ca} / \mathrm{Cit}}$ in group $C$, group $H$, and group $S_{H}$

\begin{tabular}{|c|c|c|c|c|c|c|}
\hline & \multicolumn{3}{|c|}{ Panel I } & \multicolumn{3}{|c|}{ Panel II } \\
\hline & $\begin{array}{c}\text { Group C } \\
(n=149)\end{array}$ & $\begin{array}{l}\text { Group H } \\
(n=72)\end{array}$ & $\begin{array}{l}\text { Group } S_{H} \\
(n=34)\end{array}$ & $\begin{array}{c}\text { Group C } \\
(n=149)\end{array}$ & $\begin{array}{l}\text { Group H } \\
(n=72)\end{array}$ & $\begin{array}{l}\text { Group } S_{H} \\
(n=34)\end{array}$ \\
\hline $\mathrm{U}_{\mathrm{Ca} / \mathrm{Cr}}$ & $0.10 \pm 0.09$ & $0.31 \pm 0.09$ & $0.31 \pm 0.12$ & $0.10 \pm 0.12$ & $0.30 \pm 0.08$ & $0.31 \pm 0.12$ \\
\hline Group C vs. ( $p$ value) & - & $<0.001$ & $<0.001$ & - & $<0.001$ & $<0.001$ \\
\hline Group $\mathrm{H} v s .(p$ value $)$ & - & & NS & - & - & NS \\
\hline$\Delta(95 \% \mathrm{CI})$ group C vs. & & & & - & $0.20(0.16$ to 0.23$)$ & 0.21 (0.16 to 0.24$)$ \\
\hline$\Delta(95 \% \mathrm{CI})$ group $\mathrm{H} v s$. & & & & - & - & $0.01(-0.04$ to 0.05$)$ \\
\hline $\mathrm{U}_{\mathrm{Cit} / \mathrm{Cr}}$ & $711.0 \pm 327.5$ & $898.5 \pm 351.4$ & $594.8 \pm 289.4$ & $729.1 \pm 331.7$ & $850.1 \pm 480.0$ & $626.7 \pm 283.0$ \\
\hline Group C $v s$. ( $p$ value) & - & $<0.001$ & NS & - & 0.046 & NS \\
\hline Group H vs. ( $p$ value) & - & - & $<0.001$ & - & - & 0.005 \\
\hline$\Delta(95 \% \mathrm{CI})$ group C $v s$ & & & & - & 121.1 (1.4 to 240.7$)$ & $-102.4(-251.1$ to 46.3$)$ \\
\hline$\Delta(95 \% \mathrm{CI})$ group $\mathrm{H} v s$. & & & & - & - & $-223.5(-55.5$ to -391.4$)$ \\
\hline $\mathrm{U}_{\mathrm{Ca} / \mathrm{Cit}}$ & $0.17 \pm 0.17$ & $0.41 \pm 0.23$ & $0.65 \pm 0.46$ & $0.16 \pm 0.24$ & $0.43 \pm 0.25$ & $0.64 \pm 0.23$ \\
\hline Group C vs. ( $p$ value) & - & $<0.001$ & $<0.001$ & - & $<0.001$ & $<0.001$ \\
\hline Group $\mathrm{H} v s .(p$ value $)$ & - & - & $<0.001$ & - & - & 0.001 \\
\hline$\Delta(95 \% \mathrm{CI})$ group $\mathrm{C} v s$ & & & & - & 0.27 (0.18 to 0.37$)$ & $0.48(0.36$ to 0.60$)$ \\
\hline$\Delta(95 \% \mathrm{CI})$ group $\mathrm{H} v s$. & & & & - & - & 0.21 (0.07 to 0.34$)$ \\
\hline
\end{tabular}

Panel I, shows mean \pm SD values unadjusted for age and gender. Panel II, shows the mean \pm SD values when adjusted for age and gender with mean difference and its $95 \% \mathrm{CI}$. 

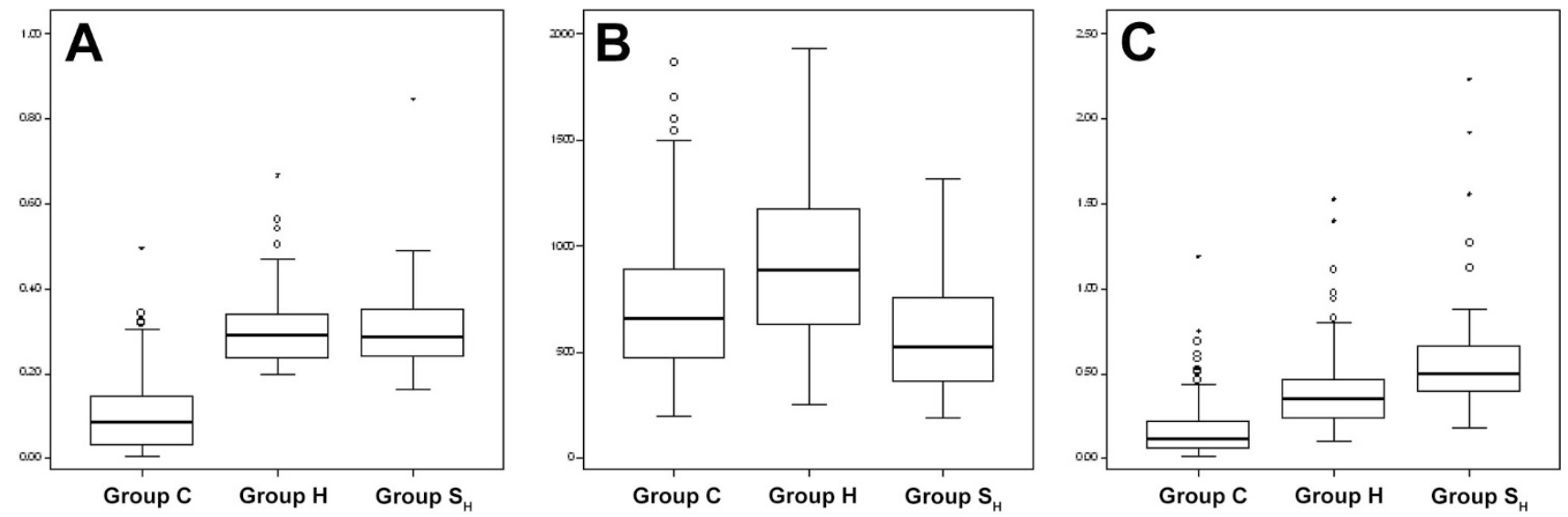

Figure 2. Box plot distribution of $(A)$ urine calcium/creatinine, $(B)$ citrate/creatinine and $(C)$ calcium/citrate ratios in groups $\mathrm{C}$ (controls), $\mathrm{H}$ (hypercalciuric without stone), and $\mathrm{S}_{\mathrm{H}}$ (hypercalciuric stone formers).

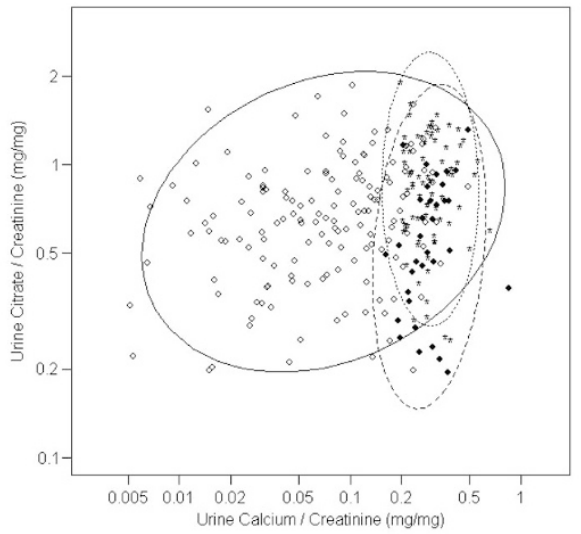

Figure 3. Distribution of urine citrate/creatinine against calcium/creatinine ratio in groups $\mathrm{C}$ (control children represented by 224 and surrounded by ellipse), $\mathrm{H}$ (hypercalciuric without stone represented by * and surrounded by $\ldots$ ellipse), and $\mathrm{S}_{\mathrm{H}}$ (hypercalciuric stone formers represented by $\bullet$ and surrounded by - - - ellipse).

decrease with age as well $(\mathrm{r}=-0.32, p<0.001)$, and $\mathrm{U}_{\mathrm{Ca} / \mathrm{Cit}}$ to be unaffected by age $(\mathrm{r}=0.06, p=0.35)$. As shown in panel II, data analysis after adjustment for both age and gender, showed the same significant differences among the three groups.

Figure 3 shows the distribution of $\mathrm{U}_{\mathrm{Cit} / \mathrm{Cr}}$ against $\mathrm{U}_{\mathrm{Ca} / \mathrm{Cr}}$ as an ellipse in children from all three groups. It shows that for every degree of hypercalciuria nonstone formers had higher urinary citrate excretion compared with stone formers.

Receiver operating characteristic curves. To establish potential "cut-off" values to discriminate between groups, ROC were constructed for $\mathrm{U}_{\mathrm{Ca} / \mathrm{Cr}}, \mathrm{U}_{\mathrm{Ci} / \mathrm{Cr}}$, and $\mathrm{U}_{\mathrm{Ca} / \mathrm{Cit}}$ ratios (Fig. 4). Assessing the stone risk between groups $\mathrm{C}$ and $\mathrm{S}_{\mathrm{H}}$, the area under ROC (AUC) was 0.939, 0.399, and 0.933 for $\mathrm{U}_{\mathrm{Ca} / \mathrm{Cr}}$, $\mathrm{U}_{\mathrm{Cit} / \mathrm{cr}}$, and $\mathrm{U}_{\mathrm{Ca} / \mathrm{Cit}}$, respectively. Between groups $\mathrm{H}$ and $\mathrm{S}_{\mathrm{H}}$, AUC was $0.484,0.747$, and 0.733 for $\mathrm{U}_{\mathrm{Ca} / \mathrm{Cr}}, \mathrm{U}_{\mathrm{Cit} / \mathrm{cr}}$, and $\mathrm{U}_{\mathrm{Ca} / \mathrm{Ci}}$, respectively, to assess the stone risk in hypercalciuric children. Between groups $\mathrm{C}$ and $\mathrm{H}$, the AUC was 0.945, 0.660 , and 0.858 for $\mathrm{U}_{\mathrm{Ca} / \mathrm{Cr}}, \mathrm{U}_{\mathrm{Cit} / \mathrm{cr}}$, and $\mathrm{U}_{\mathrm{Ca} / \mathrm{Cit}}$, respectively, for the development of symptoms related to hypercalciuria. Thus, $\mathrm{U}_{\mathrm{Ca} / \mathrm{Cit}}$ ratio showed a good discriminatory potential to differentiate across all the three groups. Based on the above analysis, combined with multilevel likelihood analyses, a $\mathrm{U}_{\mathrm{Ca} / \mathrm{Cit}}$ value of 0.326 was found to be a good cut-off point that
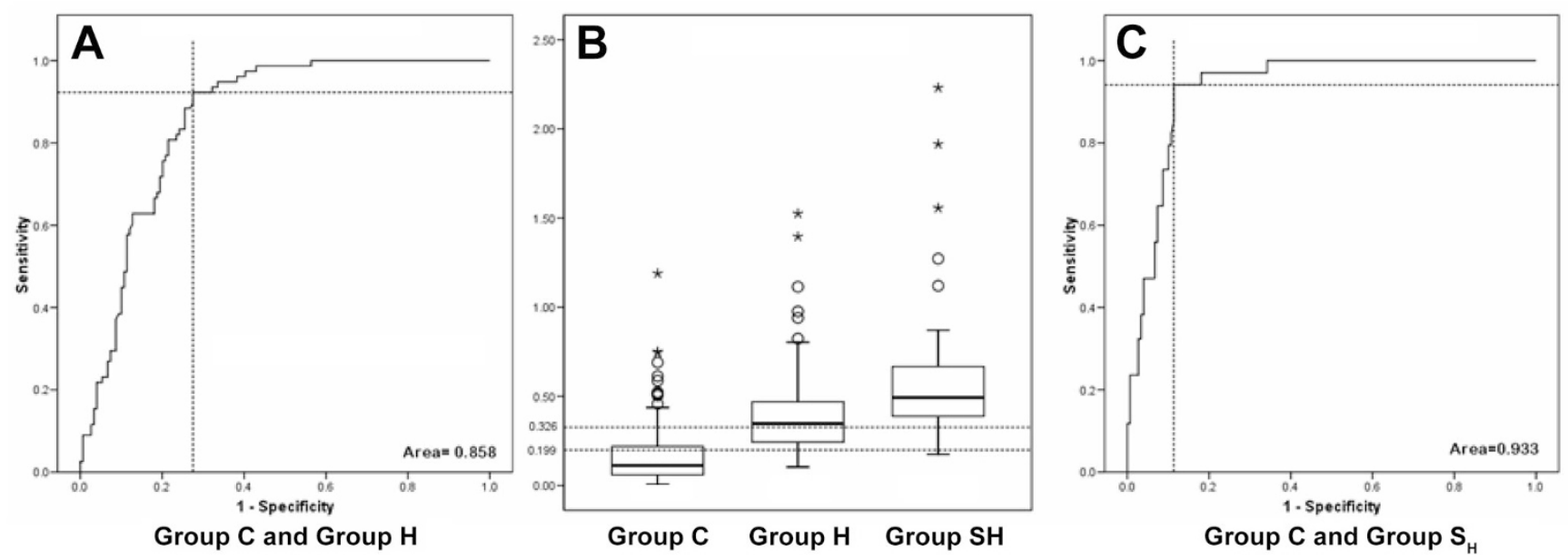

Figure 4. The figure shows the ROC for urine calcium/citrate ratio between groups $\mathrm{C}$ and $\mathrm{H}(A)$ and groups $\mathrm{C}$ and $\mathrm{S}_{\mathrm{H}}(C)$. A urine calcium/citrate ratio of 0.199 gave the best discriminatory ratio between groups $\mathrm{C}$ and $\mathrm{H}$ and 0.326 between groups $\mathrm{C}$ and $\mathrm{S}_{\mathrm{H}}$. $(B)$ Box plot distribution of urine calcium/citrate ratio in groups $\mathrm{C}, \mathrm{H}$, and $\mathrm{S}_{\mathrm{H}}$, with the lower broken line at 0.199 and the upper broken line at $0.326 \mathrm{mg} / \mathrm{g}$. 
Table 2. Multilevel likelihood ratios with sensitivities and specificities at different urine calcium/citrate $\left(U_{C a / C i t}\right)$ ratios for risk of development of stone (groups $C$ vs. $S_{H}$ and groups $H$ vs. $S_{H}$ ), and development of symptomatic hypercalciuria without stone formation (groups $C$ vs. $H$ )

\begin{tabular}{ccccc}
\hline $\begin{array}{c}\text { Urine } \mathrm{Ca} / \mathrm{Cit} \\
\text { ratio }(\mathrm{mg} / \mathrm{mg})\end{array}$ & LR+ & LR - & Sensitivity & Specificity \\
\hline $\begin{array}{l}\text { Groups } \mathrm{C} \text { and } \mathrm{S}_{\mathrm{H}} \\
>0.268\end{array}$ & 5.1 & 0.04 & 0.97 & \\
$>0.293$ & 6.2 & 0.07 & 0.94 & 0.81 \\
$>0.326$ & 8.6 & 0.07 & 0.94 & 0.85 \\
$>0.358$ & 7.5 & 0.20 & 0.82 & 0.89 \\
$>0.388$ & 7.5 & 0.20 & 0.82 & 0.89 \\
Groups H and $\mathrm{S}_{\mathrm{H}}$ & & & & \\
$>0.276$ & 1.5 & 0.09 & 0.97 & 0.35 \\
$>0.294$ & 1.5 & 0.16 & 0.94 & 0.38 \\
$>0.336$ & 1.8 & 0.18 & 0.91 & 0.49 \\
$>0.369$ & 1.8 & 0.38 & 0.79 & 0.55 \\
$>0.395$ & 2.1 & 0.40 & 0.74 & 0.64 \\
Groups C and H & & & & \\
$>0.139$ & 2.3 & 0.02 & 0.99 & 0.57 \\
$>0.169$ & 2.5 & 0.08 & 0.95 & 0.62 \\
$>0.199$ & 3.4 & 0.11 & 0.92 & 0.73 \\
$>0.229$ & 3.7 & 0.24 & 0.81 & 0.78 \\
$>0.256$ & 3.7 & 0.36 & 0.71 & 0.81 \\
\hline
\end{tabular}

produced equal sensitivity and specificity in differentiating between group $\mathrm{C}$ and group $\mathrm{S}_{\mathrm{H}}$ (Table 2, Fig. 4). $\mathrm{A} \mathrm{U}_{\mathrm{Ca} / \mathrm{Cit}}$ value of 0.199 was a good cut-off point between groups $\mathrm{C}$ and $\mathrm{H}$ (Table 2, Fig. 4), and a value of 0.336 between groups $\mathrm{H}$ and $\mathrm{S}_{\mathrm{H}}$ (Table 2, ROC data not shown).

\section{DISCUSSION}

The normal urinary citrate excretion in children has been reported to range from $>180$ to $>408 \mathrm{mg} / \mathrm{g}$ based on citrate lyase assay $(1,22)$. Indeed, in the textbook of Pediatric Nephrology 5th ed. Milliner (19) indicates the unclarity of normative data of urine citrate by quoting both values of 180 and $400 \mathrm{mg} / \mathrm{g}$. In this study, urinary citrate excretion of 180 and $408 \mathrm{mg} / \mathrm{g}$ equal approximately the 5 th and 25 th percentiles, respectively, in our healthy controls (Fig. 1). Assuming that nowadays, the methodology to analyze urine citrate is standardized, it is unacceptable to have such different values. Our laboratory uses the citrate lyase assay, as do other major reference laboratories. When compared with Mayo Clinic methodology, which regards hypocitraturia as $<180 \mathrm{mg} / \mathrm{g}$ creatinine, our laboratory shows excellent mean bias, slope, intercept, and $\mathrm{R}^{2}$ values of $0.7,0.998,0.801$, and 0.996, respectively (data not shown). In the past, Miller and Stapleton (22) found the threshold of 2SD below the mean for urine citrate/creatinine in children to be $182 \mathrm{mg} / \mathrm{g}$. These values are consistent with our finding of the 5th percentile in controls of $176 \mathrm{mg} / \mathrm{g}$ (Fig. 1). Because of the fact that we found a weak inverse correlation between $\mathrm{U}_{\mathrm{Cit} / \mathrm{Cr}}$ and age, we further analyzed the data dividing controls into two groups based on median age of 9.75 ; the 5 th percentile of $\mathrm{U}_{\mathrm{Cit} / \mathrm{Cr}}$ in those younger than 9.75 was $178.6 \mathrm{mg} / \mathrm{g}$ while in the older subjects it was $145.8 \mathrm{mg} / \mathrm{g}$ indicating that in pediatric age groups $\mathrm{U}_{\mathrm{Cit} / \mathrm{Cr}}>180 \mathrm{mg} / \mathrm{g}$ can be regarded as normal. Indeed, Norman et al. (23) found urine citrate/creatinine to be $<75 \mathrm{mg} / \mathrm{g}$ in nine children with complete and incomplete distal renal tubular acidosis. On the other hand, using the reference value of $400 \mathrm{mg} / \mathrm{g}$ as was recently done by VanDervoort $e t$ al. (1) would have rendered $25 \%$ of our control population and $44.3 \%$ of our stone formers as hypocitraturic. Their study, however, which not surprisingly defined $52 \%$ of their pediatric stone formers to be hypocitraturic, did not use a control group to support the high cut-off value (1). It is important to note that our data were based on random urine sample. However, as aforementioned the value of $180 \mathrm{mg} / \mathrm{g}$ is also used for $24-\mathrm{h}$ urine collection at the Mayo Clinic. Furthermore, we have shown in the past a correlation coefficient value of 0.96 between our random mid-day urine chemistries and 24-h collection (24). Thus, combining the findings in our study, previous studies and reference values used in other laboratories, and for the maintenance of consistency we recommend using urine citrate/creatinine ratio of $180 \mathrm{mg} / \mathrm{g}$ as the lower limit of normal in school-age children.

Parks and Coe (25) found that compared with normal people, adults with urolithiasis had a high level of urine calcium for any given level of urine citrate, and no other urinary constituent could improve on this relationship. Thus, it may not be the absolute urinary calcium or citrate concentrations that determine the risk of stone formation but rather the relative excess of calcium over citrate. Similarly, Cupisti et al. (26) found that stone formers had higher urinary calcium excretion and low citrate excretion, which was more marked in recurrent stone formers. As early as 1976, Welshman and McGeown (14) had found urinary calcium/citrate ratio to be different in normal adult subjects and stone formers but found a difference between the two genders. Subsequently, Nikkila et al. (16) documented urinary citrate/calcium excretion to be significantly higher in stone-formers $(0.25 \pm 0.03 \mathrm{mmol} /$ $\mathrm{mmol})$ than in control subjects $(1.25 \pm 0.31 \mathrm{mmol} / \mathrm{mmol})$. This remained true for both genders separately but the absolute values were lower in females. In the study by Hobarth and Hofbauer (15), urinary calcium/citrate $(\mathrm{mmol} / \mathrm{mmol})$ ratio increased from $1.7 \pm 0.45$ in normal adults to $3.1 \pm 0.49$ in single stone formers and to $5.3 \pm 1.1$ in recurrent stone formers, and in contrast to the above two studies no gender difference was observed.

Therefore, because of the inconsistencies in the adult studies regarding the effects of age and gender on urinary excretion of citrate it was felt that the clinical use of urine calcium/ citrate ratio is of limited value (27). In contrast, in our study $\mathrm{U}_{\mathrm{Ca} / \mathrm{Cit}}$ ratio was not influenced by either age or gender in children when analyzed with and without adjustment for these factors (Table 1). Gender by itself had no influence on either urinary calcium/creatinine, citrate/creatinine, or calcium/ citrate ratios as was found in other pediatric studies $(17,21,28)$. Indeed, in contrast to the adult population, the absence of preponderance of urolithiasis in boys in our study and others indirectly further supports the lack of gender influence in the pediatric population $(29,30)$. Similar to previous studies, we found age to have an effect on $\mathrm{U}_{\mathrm{Ca} / \mathrm{Cr}}$ and $\mathrm{U}_{\mathrm{Cit} / \mathrm{Cr}}$; however, because both were in the same direction, namely decreasing as age advanced, they ended up having no effect on $\mathrm{U}_{\mathrm{Ca} / \mathrm{Cit}}$ ratio $(20,21,31,32)$. In summary, we found 
that $\mathrm{U}_{\mathrm{Ca} / \mathrm{Cit}}$ ratio could discriminate between normal children and stone formers, and in contrast to adults was not affected by either age or gender, which simplifies its use as a clinical parameter in children. These results are consistent with the recent findings by DeFoor et al. (18) that urine calcium/citrate ratio in children is the best parameter to assess the risk for recurrent calcium stone formation.

As often happens in clinical practice, not all stones were captured, hence no stone analysis was available in 14 of the 34 stone forming children (33). However, when the group of 20 children with known stone composition was compared with control children, the findings were the same as for the whole stone group (data not shown). Indeed, calcium stone has become the most common form of stone in developed countries $(33,34)$. The likelihood of the remaining 14 hypercalciuric stone-forming children as not to have a calcium-based stone is low as we had included only children with hypercalciuria with radiologically documented stone and had excluded children with cystine, uric acid, and struvite stones, and those with hyperoxaluria or hypocitraturia, and children with history of UTI, or anatomic and functional abnormalities in the urinary and gastro intestinal tracts. Thus, we believe that it was acceptable to use all 34 children in the stone group under the pathophysiologic umbrella of hypercalciuric stone formers.

The hypercalciuric nonstone formers presented with either voiding symptoms or microscopic hematuria but did not have symptoms attributable to urolithiasis. Imaging studies confirming the absence of stone were available in only $45 \%$ of them. We believe that the possibility of having a stone in some of the other $55 \%$ is low due to the observation that the incidence of stone formation in hypercalciuric children is low $(5 \%)$ in the absence of gross hematuria, severe lower abdominal, or flank pain (35). There was no difference in hypercalciuric nonstone formers for gender, age, $\mathrm{U}_{\mathrm{Ca} / \mathrm{Cr}}$ and $\mathrm{U}_{\mathrm{Cit} / \mathrm{Cr}}$ between children who had the imaging study $v s$. no imaging study (data not shown).

As expected, compared with normal, hypercalciuric children had higher urinary $\mathrm{U}_{\mathrm{Ca} / \mathrm{Cr}}$ ratio but quite interestingly there was no difference in $\mathrm{U}_{\mathrm{Ca} / \mathrm{Cr}}$ between hypercalciuric stone formers and nonstone formers (Table 1, Fig. 2). On the other hand, mean $\mathrm{U}_{\mathrm{Cit} / \mathrm{Cr}}$ in group $\mathrm{H}$ was $34 \%$ higher than in hypercalciuric stone formers (Table 1). Consequently, compared with controls $\mathrm{U}_{\mathrm{Ca} / \mathrm{Cit}}$ ratio was $\sim 2.5$ times higher in the hypercalciuric children without stones and $\sim 4$ times higher in the stone formers (Table 1, Fig. 2). Furthermore, as shown in Fig. 3, compared with hypercalciuric stone formers urine citrate excretion in hypercalciuric children without stone was much higher at any given value of calcium excretion. Thus, our data suggest that a high urinary citrate excretion in hypercalciuric children has a protective role against stone formation. Citrate in urine is well known to have an inhibitory role in calcium stone formation, and citrate preparations are currently used routinely in the treatment of patients with calcium stones $(9,27,36)$. This finding may have an importance in both estimating the risk of the hypercalciuric child to develop stones, and possibly as a guideline for treatment (vide infra). An important question is whether the relative hypocitraturia in stone formers, compared with nonstone formers, was the cause or the effect of hypercalciuria. Multiple studies showed acidification defect in hypercalciuric stone formers, which in some may result in hypocitraturia (37-39). BonillaFelix et al. (37) found that among hypercalciuric children only those with stones had an acidification defect. However, not all stone formers had an acidification defect and no correlation was found between the latter and urine citrate. In adult studies, Wikström et al. (38) found $22 \%$ of 389 stone formers to have an acidification defect; however, in the majority of them another etiology rather than primary hypercalciuria was observed. In another study based on ammonium chloride loading test, Osther et al. (39) found an acidification defect in only $12.7 \%$ of stone formers, the majority of whom had bilateral stone disease. Nevertheless, as stated by the latter group "regardless of whether the acidification defect is primary or secondary to stone formation, all renal stone formers with an acidification defect can benefit from prophylactic alkali therapy" (39). We also agree that even if the diagnostic value of $\mathrm{U}_{\mathrm{Ca} / \mathrm{Cit}}$ is questioned, it can still serve as a therapeutic yardstick.

The beneficial effect of treatment with potassium citrate in decreasing recurrence of new stones, growth of residual stone fragments after lithotripsy and in stone-forming children with hypocitraturia is well established (40-44). In a preliminary study in nine healthy children, treatment with potassium citrate at 0.5 or $1 \mathrm{mEq} \mathrm{K} / \mathrm{kg} / \mathrm{d}$ resulted in an increase in urinary citrate excretion, but the higher dose also caused a significant increase in urine $\mathrm{pH}$ (Auron A et al. Effects of low vs. high dose potassium citrate on urine chemistry and acid-base status. 40th Annual Renal Meeting of American Society of Nephrology, November 2-5, 2007 in San Francisco, SU-FC026). Indeed, there is a concern that the increase in urine $\mathrm{pH}$ observed with citrate therapy may promote urinary supersaturation and activity product of calcium phosphate, thus defeating the purpose of treatment (45). Although as aforementioned potassium citrate is being used effectively in the prevention of urolithiasis, there is no data on how to titrate its dose (46). Our ROC data and multilevel likelihood table (Fig. 4, Table 2) show that a $\mathrm{U}_{\mathrm{Ca} / \mathrm{Cit}}$ ratio of 0.326 gives a good discrimination point between normal and stone formers and a $\mathrm{U}_{\mathrm{Ca} / \mathrm{Cit}}$ ratio of 0.199 between hypercalciuric children and control children. Thus $\mathrm{U}_{\mathrm{Ca} / \mathrm{Cit}}$ ratio of $<0.326$ could be a target goal for hypercalciuric stone formers receiving potassium citrate or other therapy. Providing support for this cut-off value is the very similar value of 0.336 differentiating hypercalciuric stone formers from nonstone formers (Table 2). However, as shown in Table 2 , in reality there is a continuum effect that suggests that the lower the $\mathrm{U}_{\mathrm{Ca} / \mathrm{Cit}}$ value the lower is the stone risk. Another conclusion from the above data are that it might not be needed to fully correct hypercalciuria in stone formers if one can maintain satisfactory urine citrate concentration, thus keeping the ratio of $\mathrm{U}_{\mathrm{Ca} / \mathrm{Cit}}$ low enough to protect from stone formation. As our proposed $\mathrm{U}_{\mathrm{Ca} / \mathrm{Cit}}$ cut-off values are based on retrospective data, there will be a need to validate them in prospective studies, taking into consideration also urine $\mathrm{pH}$, which was not available for analysis in this study.

In summary, this study provides the normal urine citrate/ creatinine percentile distribution in children 5-18 y old, and the establishment of the 5 th percentile at $180 \mathrm{mg} / \mathrm{g}$. We found 
urinary citrate to be important in protecting hypercalciuric children form stone formation, and $\mathrm{U}_{\mathrm{Ca} / \mathrm{Cit}}$ ratio to be helpful in discriminating between healthy and stone forming children. Given its advantage of not being influenced by gender, age, or muscle mass (due to absence of creatinine in the equation) $\mathrm{U}_{\mathrm{Ca} / \mathrm{Cit}}$ has the potential to be used as a clinical tool to assess the risk of urolithiasis in children and as a therapeutic target. The latter may provide a better guidance for potassium citrate therapy, where unnecessarily high doses that might lead to alkaline urine should be avoided. Further prospective studies in children with urolithiasis using the recommended cut-off values will be required to confirm our findings.

Acknowledgments. The authors thank Nancy Wilson, Patricia A. Cudmore, Sylvia DiMaggio, and Michal Alon for laboratory assistance and Stephen D. Simon, Ph.D. for statistical assistance in completing the study.

\section{REFERENCES}

1. VanDervoort K, Wiesen J, Frank R, Vento S, Crosby V, Chandra M, Trachtman H 2007 Urolithiasis in pediatric patients: a single center study of incidence, clinical presentation and outcome. J Urol 177:2300-2305

2. Srivastava T, Alon US 2005 Urolithiasis in adolescent children. Adolesc Med Clin 16:87-109

3. Nicar MJ, Hill K, Pak CY 1987 Inhibition by citrate of spontaneous precipitation of calcium oxalate in vitro. J Bone Miner Res 2:215-220

4. Kok DJ, Papapoulos SE, Bijvoet OL 1986 Excessive crystal agglomeration with low citrate excretion in recurrent stone-formers. Lancet 1:1056-1058

5. Meyer JL, Smith LH 1975 Growth of calcium oxalate crystals. II. Inhibition by natural urinary crystal growth inhibitors. Invest Urol 13:36-39

6. Meyer JL, Thomas WC Jr 1982 Trace metal-citric acid complexes as inhibitors of calcification and crystal growth. I. Effects of $\mathrm{Fe}(\mathrm{III}), \mathrm{Cr}$ (III) and $\mathrm{Al}(\mathrm{III})$ complexes on calcium phosphate crystal growth. J Urol 128:1372-1375

7. Sutor DJ, Percival JM, Doonan S 1978 Isolation and identification of some urinary inhibitors of calcium phosphate formation. Clin Chim Acta 89:273-278

8. Pak CY 1994 Citrate and renal calculi: an update. Miner Electrolyte Metab 20:371377

9. Bisaz S, Felix R, Neuman WF, Fleisch H 1978 Quantitative determination of inhibitors of calcium phosphate precipitation in whole urine. Miner Electrolyte Metab 1:74-83

10. Lieske JC, Coe FL 1996 Urinary inhibitors and renal stone formation. In: Preminger GM (ed) Kidney Stones: Medical and Surgical Management. Lippincott-Raven, Philadelphia, pp 65-113

11. Pak CY, Fuller C 1986 Idiopathic hypocitraturic calcium-oxalate nephrolithiasis successfully treated with potassium citrate. Ann Intern Med 104:33-37

12. Pak CY, Fuller C, Sakhaee K, Preminger GM, Britton F 1985 Long-term treatment of calcium nephrolithiasis with potassium citrate. J Urol 134:11-19

13. Robinson MR, Leitao VA, Haleblian GE, Scales CD Jr, Chandrashekar A, Pierre SA, Preminger GM 2009 Impact of long-term potassium citrate therapy on urinary profiles and recurrent stone formation. J Urol 181:1145-1150

14. Welshman SG, McGeown MG 1976 Urinary citrate excretion in stone-formers and normal controls. Br J Urol 48:7-11

15. Hobarth K, Hofbauer J 1991 Value of routine citrate analysis and calcium/citrate ratio in calcium urolithiasis. Eur Urol 19:165-168

16. Nikkila M, Koivula T, Jokela H 1989 Urinary citrate excretion in patients with urolithiasis and normal subjects. Eur Urol 16:382-385

17. al-Qadreh A, Athanasopoulou H, Voskaki I 1992 Inhibitors of stone formation in hypercalciuric children with and without stone disease. Eur Urol 21:227-230
18. DeFoor W, Minevich E, Jackson E, Reddy P, Clark C, Sheldon C, Asplin J 2008 Urinary metabolic evaluations in solitary and recurrent stone forming children. J Urol 179:2369-2372

19. Milliner DS 2004 Urolithiasis. In: Avner ED, Harmon WE, Niaudet P (eds) Pediatric Nephrology. Lippincott, Williams and Wilkins, Philadelphia, pp 1091-1111

20. So NP, Osorio AV, Simon SD, Alon US 2001 Normal urinary calcium/creatinine ratios in African-American and Caucasian children. Pediatr Nephrol 16:133-139

21. Matos V, van Melle G, Boulat O, Markert M, Bachmann C, Guignard JP 1997 Urinary phosphate/creatinine, calcium/creatinine, and magnesium/creatinine ratios in a healthy pediatric population. J Pediatr 131:252-257

22. Miller LA, Stapleton FB 1985 Urinary citrate excretion in children with hypercalciuria. J Pediatr 107:263-266

23. Norman ME, Feldman NI, Cohn RM, Roth KS, McCurdy DK 1978 Urinary citrate excretion in the diagnosis of distal renal tubular acidosis. J Pediatr 92:394-400

24. Richmond W, Colgan G, Simon S, Stuart-Hilgenfeld M, Wilson N, Alon US 2005 Random urine calcium/osmolality in the assessment of calciuria in children with decreased muscle mass. Clin Nephrol 64:264-270

25. Parks JH, Coe FL 1986 A urinary calcium-citrate index for the evaluation of nephrolithiasis. Kidney Int 30:85-90

26. Cupisti A, Morelli E, Lupetti S, Meola M, Barsotti G 1992 Low urine citrate excretion as main risk factor for recurrent calcium oxalate nephrolithiasis in males. Nephron 61:73-76

27. Caudarella R, Vescini F, Buffa A, Stefoni S 2003 Citrate and mineral metabolism: kidney stones and bone disease. Front Biosci 8:S1084-S1106

28. Ratan SK, Bhatnagar V, Mitra DK, Basu N, Malhotra LK 2002 Urinary citrate excretion in idiopathic nephrolithiasis. Indian Pediatr 39:819-825

29. Stapleton FB, McKay CP, Noe HN 1987 Urolithiasis in children: the role of hypercalciuria. Pediatr Ann 16:980-981

30. Coe FL, Evan A, Worcester E 2005 Kidney stone disease. J Clin Invest 115:25982608

31. Koyun M, Güven AG, Filiz S, Akman S, Akbas H, Baysal YE, Dedeoglu N 2007 Screening for hypercalciuria in schoolchildren: what should be the criteria for diagnosis? Pediatr Nephrol 22:1297-1301

32. Blau N, Matasovic A, Lukasiewicz-Wedlechowicz A, Heizmann CW, Leumann E 1998 Simultaneous determination of oxalate, glycolate, citrate, and sulfate from dried urine filter paper spots in a pediatric population. Clin Chem 44:1554-1556

33. Alon US, Zimmerman H, Alon M 2004 Evaluation and treatment of pediatric idiopathic urolithiasis-revisited. Pediatr Nephrol 19:516-520

34. Trinchieri A 1996 Epidemiology of urolithiasis. Arch Ital Urol Androl 68:203-249

35. Polito C, La Manna A, Cioce F, Villani J, Nappi B, Di Toro R 2000 Clinical presentation and natural course of idiopathic hypercalciuria in children. Pediatr Nephrol 15:211-214

36. Bisaz S, Felix R, Hansen NM, Fleisch H 1976 Disaggregation of hydroxyapatite crystals. Biochim Biophys Acta 451:560-566

37. Bonilla-Felix M, Villegas-Medina O, Vehaskari VM 1994 Renal acidification in children with idiopathic hypercalciuria. J Pediatr 124:529-534

38. Wikström B, Backman U, Danielson BG, Fellström B, Johansson G, Ljunghall S 1983 Ambulatory diagnostic evaluation of 389 recurrent renal stone formers. A proposal for clinical classification and investigation. Klin Wochenschr 61:85-90

39. Osther PJ, Hansen AB, Røhl HF 1989 Screening renal stone formers for distal renal tubular acidosis. Br J Urol 63:581-583

40. Barcelo P, Wuhl O, Servitge E, Rousaud A, Pak CY 1993 Randomized double-blind study of potassium citrate in idiopathic hypocitraturic calcium nephrolithiasis. J Urol 150:1761-1764

41. Ettinger B, Pak CY, Citron JT, Thomas C, Adams-Huet B, Vangessel A 1997 Potassium-magnesium citrate is an effective prophylaxis against recurrent calcium oxalate nephrolithiasis. J Urol 158:2069-2073

42. Tekin A, Tekgul S, Atsu N, Bakkaloglu M, Kendi S 2002 Oral potassium citrate treatment for idiopathic hypocitruria in children with calcium urolithiasis. J Urol 168:2572-2574

43. Hofbauer J, Höbarth K, Szabo N, Marberger M 1994 Alkali citrate prophylaxis in idiopathic recurrent calcium oxalate urolithiasis-a prospective randomized study. Br J Urol 73:362-365

44. Sarica K, Erturhan S, Yurtseven C, Yagci F 2006 Effect of potassium citrate therapy on stone recurrence and regrowth after extracorporeal shockwave lithotripsy in children. J Endourol 20:875-879

45. Pak CY, Koenig K, Khan R, Haynes S, Padalino P 1992 Physicochemical action of potassium-magnesium citrate in nephrolithiasis. J Bone Miner Res 7:281-285

46. Alon US 2008 Medical treatment of pediatric urolithiasis. Pediatr Nephrol, in press 